\title{
Facile Synthesis of Antimony Tungstate Nanosheets as Anodes for Lithium-Ion Batteries
}

\author{
Yong Liu ${ }^{1,2, *,+} \mathbb{D}$, Yue Wang ${ }^{1, \dagger}{ }^{,}$Fei Wang ${ }^{1}$, Zhenxiao Lei ${ }^{1}$, Wanhong Zhang ${ }^{1}$, Kunming Pan ${ }^{2}$, \\ Jing Liu ${ }^{1,3}$, Min Chen ${ }^{4}$, Guangxin Wang ${ }^{1, *}$, Fengzhang Ren ${ }^{1}$ and Shizhong Wei ${ }^{2, *}$ \\ 1 Collaborative Innovation Center of Nonferrous Metals of Henan Province, Henan Key Laboratory of \\ Non-Ferrous Materials Science \& Processing Technology, School of Materials Science and Engineering, \\ Henan University of Science and Technology, Luoyang 471023, China; 18438616683@163.com (Y.W.); \\ 15737937208@163.com (F.W.); 151402090112@stu.haust.edu.cn (Z.L.); zhangwh@haust.edu.cn (W.Z.); \\ 181414120220@stu.haust.edu.cn (J.L.); renfz@haust.edu.cn (F.R.) \\ 2 National Joint Engineering Research Center for Abrasion Control and Molding of Metal Materials, \\ Henan Key Laboratory of High-Temperature Structural and Functional Materials, Henan University of \\ Science and Technology, Luoyang 471023, China; pankunming2008@163.com \\ 3 School of Agriculture, Henan University of Science and Technology, Luoyang 471023, China \\ 4 School of Materials Science and Energy Engineering, Foshan University, Foshan 528000, China; \\ minchen1981@126.com \\ * Correspondence: liuyong209@haust.edu.cn (Y.L.); wanggx2016@126.com (G.W.); wsz@haust.edu.cn (S.W.) \\ + These authors contributed equally to this work.
}

Received: 4 November 2019; Accepted: 20 November 2019; Published: 25 November 2019

\begin{abstract}
Lithium-ion batteries (LIBs) have been widely used in the fields of smart phones, electric vehicles, and smart grids. With its opened Aurivillius structure, tungstate antimony oxide $\left(\mathrm{Sb}_{2} \mathrm{WO}_{6}\right.$, SWO), constituted of $\left\{\mathrm{Sb}_{2} \mathrm{O}_{2}\right\}^{2 \mathrm{n}+}$ and $\left\{\mathrm{WO}_{4}\right\}^{2 \mathrm{n}-}$, is rarely investigated as an anode for lithium-ion batteries. In this work, $\mathrm{Sb}_{2} \mathrm{WO}_{6}$ with nanosheets morphology was successfully synthesized using a simple microwave hydrothermal method and systematically studied as an anode for lithium-ion batteries. The optimal SWO (SWO-60) exhibits a high specific discharge capacity and good rate capability. The good electrochemical performance could be ascribed to mesoporous nanosheets morphology, which is favorable for the penetration of the electrolyte and charge transportation. The results show that this nanostructured SWO is a promising anode material for LIBs.
\end{abstract}

Keywords: antimony tungstate nanosheets; microwave hydrothermal method; lithium-ion batteries; anode; cycling performance; rate capability

\section{Introduction}

Lithium-ion batteries (LIBs) are widely used in the fields of portable devices, electric cars, and smart grids due to of their advantages, which include a higher working voltage and longer cycle life than many other energy storage systems [1-9]. However, the energy density of LIBs is still limited and may not meet demand, especially in the fields of high-performance electric vehicles and unmanned aerial vehicles, effectively hindering further development in these fields [10-17]. The reversible discharge capacity of commercial anodes (graphite), which is only $\sim 372 \mathrm{mAh} \mathrm{g}^{-1}$, cannot meet the increasing demands for high-energy-density applications [18-26]. The use of proper anode materials with high capacities is a good strategy to solve the problem of LIBs [17]. Therefore, it is urgent that high-capacity negative materials for rechargeable lithium-ion batteries are developed and optimized.

As a potentially promising anode material for LIBs, transition metal oxides (TMO) have attracted broad attention due to their higher reversible capacity and proper redox voltage $[25,26]$. As one kind of TMO, oxysalts of tungsten, such as $\mathrm{ZnWO}_{4}$ [27], $\mathrm{CaWO}_{4}$ [28], $\mathrm{FeWO}_{4}$ [29], and $\mathrm{Bi}_{2} \mathrm{WO}_{6}$ [30,31], 
have been used as negative materials for lithium-ion batteries. For example, Zhang and colleagues [30] investigated $\mathrm{Bi}_{2} \mathrm{WO}_{6} /$ graphene composite materials, which can exhibit $715.2 \mathrm{mAh} \mathrm{g}^{-1}$ at the first discharge at $50 \mathrm{~mA} \mathrm{~g}^{-1}$ and show excellent cycling performance. As a kind of tungstate, $\mathrm{Sb}_{2} \mathrm{WO}_{6}$ has a wide application in the field of photocatalysis [32-34] because of its unique layered structure and physicochemical properties [35,36]. Additionally, $\mathrm{Sb}_{2} \mathrm{WO}_{6}$ was recently reported as an anode for sodium-ion batteries with superior cycling and rate performance, delivering about $350 \mathrm{~mA} \mathrm{~h} \mathrm{~g}^{-1}$ after 100 cycles at $0.2 \mathrm{~A} \mathrm{~g}^{-1}$ [35]. Furthermore, the microwave hydrothermal method is well-known for effectively reducing reaction time and saving energy [37]. However, to the best of our knowledge, $\mathrm{Sb}_{2} \mathrm{WO}_{6}$ is rarely systematically investigated as an anode material for LIBs.

Herein, $\mathrm{Sb}_{2} \mathrm{WO}_{6}$ nanosheets were successfully fabricated through a microwave hydrothermal method, and their electrochemical performance was systematically studied as a negative electrode for LIBs. When used as a negative electrode material for LIBs, the optimal as-synthesized tungstate antimony oxide (SWO) sample exhibits a high reversible specific discharge capacity of $\sim 698.95 \mathrm{mAh} \mathrm{g}^{-1}$ and remains at $424.22 \mathrm{mAh} \mathrm{g}^{-1}$ after 100 cycles at $0.2 \mathrm{~A} \mathrm{~g}^{-1}$. Furthermore, it exhibits a good rate performance.

\section{Materials and Methods}

\subsection{Fabrication of $\mathrm{Sb}_{2} \mathrm{WO}_{6}$}

All chemicals were directly used after purchase without further purification. As per the typical method, $0.1045 \mathrm{~g} \mathrm{Na}_{2} \mathrm{WO}_{4} \cdot 2 \mathrm{H}_{2} \mathrm{O}$ and $0.1446 \mathrm{~g} \mathrm{SbCl}_{3}$ were separately dissolved in $20 \mathrm{~mL}$ and $10 \mathrm{~mL}$ of distilled water, respectively, and then stirred for $15 \mathrm{~min}$. The $\mathrm{Na}_{2} \mathrm{WO}_{4} \cdot 2 \mathrm{H}_{2} \mathrm{O}$ solution was added to the $\mathrm{SbCl}_{3}$ solution until a yellow suspension was formed, after which it was stirred for another $30 \mathrm{~min}$. Next, the solution was added to a microwaveable water kettle $(50 \mathrm{~mL})$ and fixed in a microwave hydrothermal synthesizer (XH800, Beijing, China). A continuous microwave heating mode was set up to provide a stable heat source at a microwave power of $500 \mathrm{~W}$. The temperature of the mixed solution quickly rose from room temperature to $160^{\circ} \mathrm{C}$ and was maintained at $160^{\circ} \mathrm{C}$ for different lengths of time (45 $\mathrm{min}, 60 \mathrm{~min}$, and $75 \mathrm{~min}$, which were denoted as SWO-45, SWO-60, and SWO-75, respectively). Afterwards, the resulting precipitates were filtered and washed several times with absolute ethanol and deionized water, and then the collected precipitation was dried overnight by lyophilization (LGJ-12, Beijing, China).

\subsection{Material Characterization}

Scanning electron micrographs were collected on a field-emission scanning electron microscope (FESEM, JSM-5610LV, JEOL, Akishima, Japan), and transmission electron micrographs and selected area electron diffraction patterns (SAED) were collected on a transmission electron microscope (TEM, JSM-2100F, $200 \mathrm{kV}$, Hitachinaka, Naka, Japan) to visually observe morphologies, particle sizes, etc. The crystallographic phase of the as-synthesized samples was characterized by $\mathrm{X}$-ray diffraction (XRD, Bruker D8 ADVANCE, $\mathrm{Cu} k \alpha$ source), and the $2 \theta$-angle ranged from $10^{\circ}-80^{\circ}$. Nitrogen adsorption-desorption isotherms were acquired by the Brunauer-Emmett-Teller (BET) method at $77 \mathrm{~K}$ from a Quadrasorb SI analyzer, and pore size distribution originated from the desorption branch based on the Barrett-Joyner-Halenda (BJH) theory.

\subsection{Electrochemical Measurements}

The electrochemical lithium storage performances were evaluated through a two-electrode system. Specifically, high-purity lithium foil $(15.8 \mathrm{~mm} \times 0.5 \mathrm{~mm})$ was employed as the counter and reference electrode. After dissolving carboxymethylcellulose sodium (binder, $\mathrm{CMC}$ ) in deionized water and stirring gently for $24 \mathrm{~h}$ to fabricate the working electrode, the slurry was made by mixing the $\mathrm{Sb}_{2} \mathrm{WO}_{6}$ samples, carbon black (Super P), and CMC at a weight ratio of 70:20:10. After fully stirring, the steady slurry was coated onto conductive copper foil and dried at $80^{\circ} \mathrm{C}$ for $5 \mathrm{~h}$. The dried electrodes were cut 
into a $12 \mathrm{~mm}$-diameter disk to serve as a working electrode, and the active material loading in each disk was weighed to be $0.9-1.1 \mathrm{mg}$, corresponding to $0.8-0.97 \mathrm{mg} \mathrm{cm}^{-2}$. The batteries were assembled in the glove box with argon atmosphere. During assembly, the Celgard 2400 was used as a separator, while the electrolyte was made by dissolving $1 \mathrm{M} \mathrm{LiPF}_{6}$ into a solvent consisting of ethylene carbonate (EC) and dimethyl carbonate (DMC) (EC/DMC, 1:1 in volume ratio). The galvanostatic discharge-charge measurements were performed on a LAND CT2001A in the voltage window from 0.01 to $3.0 \mathrm{~V}$ (vs. $\mathrm{Li} / \mathrm{Li}^{+}$). An electrochemical impedance spectroscopy (EIS) was conducted ranging from $100 \mathrm{kHz}$ to 0.01 $\mathrm{Hz}$, and the cyclic voltammetry $(\mathrm{CV})$ was measured in the range of $0.01-3.0 \mathrm{~V}\left(\mathrm{vs} . \mathrm{Li} / \mathrm{Li}^{+}\right.$) at $0.5 \mathrm{mV} \mathrm{s}^{-1}$. The two electrochemical tests discussed above were carried out on an electrochemistry workstation (CHI660E, Shanghai, China).

\section{Results and Discussion}

\subsection{Structure and Morphology}

Figure 1a illustrates the XRD patterns of the $\mathrm{Sb}_{2} \mathrm{WO}_{6}$ samples synthesized by a microwave hydrothermal method at different microwave heating times (45 min, $60 \mathrm{~min}$, and $75 \mathrm{~min}$ ). The peaks at $26.9^{\circ}(211), 29.2^{\circ}(002), 32.9^{\circ}(310)$, and $36.6^{\circ}$ (112) agree well with the diffraction pattern of $\mathrm{Sb}_{2} \mathrm{WO}_{6}$ (JCPDS card No.50-1553) [29]. Furthermore, no additional phase could be found, indicating that pure $\mathrm{Sb}_{2} \mathrm{WO}_{6}$ was successfully synthesized.
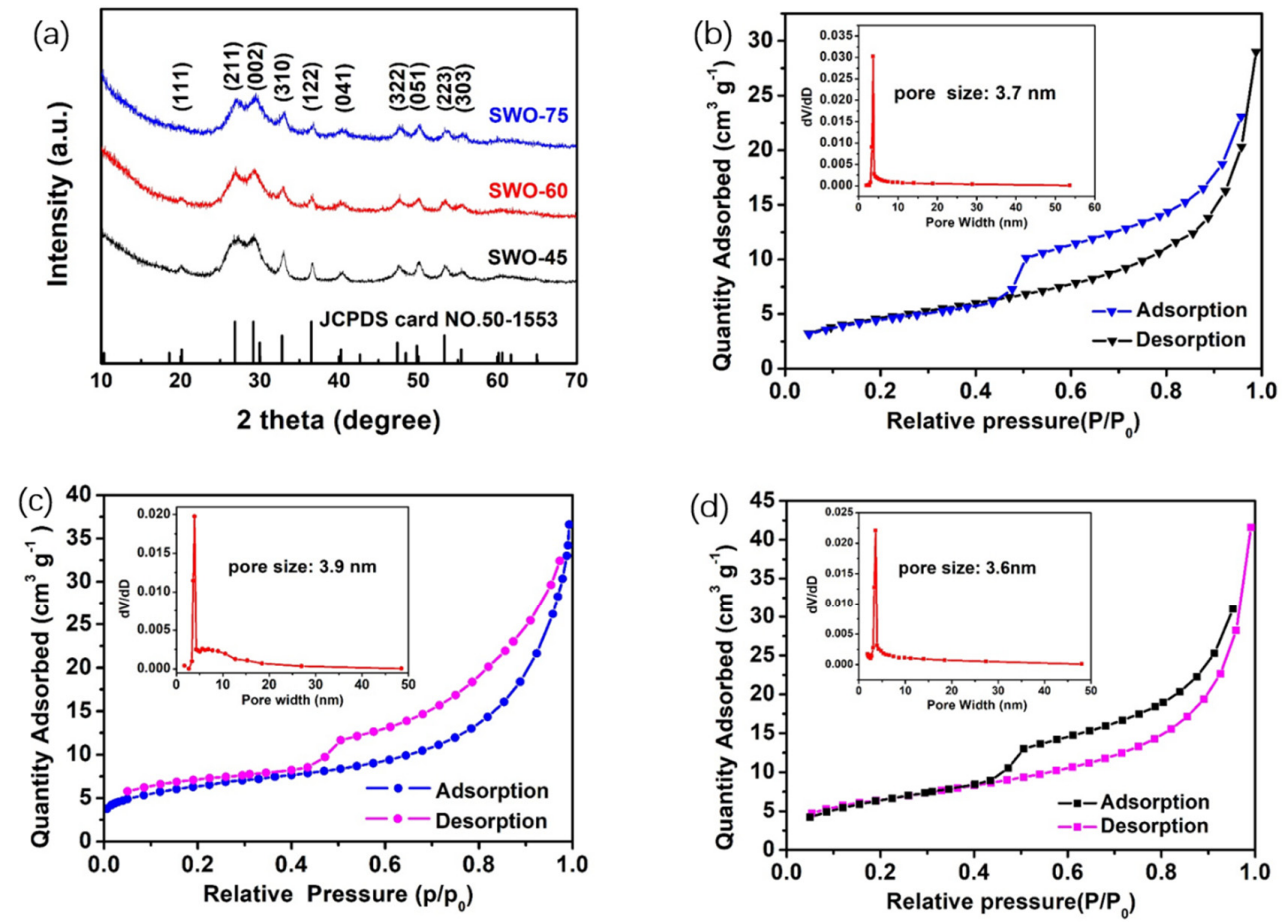

Figure 1. (a) X-ray diffractometry pattern of as-synthesized tungstate antimony oxide (SWO)-45, SWO-60, and SWO-75 samples. Nitrogen adsorption-desorption isotherms and pore-size distribution (inset) of (b) SWO-45, (c) SWO-60, and (d) SWO-75 samples.

The $\mathrm{Sb}_{2} \mathrm{WO}_{6}$ samples synthesized by the different microwave heating times (SWO-45, SWO-60, and SWO-75) were also characterized by a nitrogen adsorption-desorption isotherms measurement. As depicted in Figure $1 b-d$, typical IV-type isotherms were obtained, indicating that almost no micropores existed in the $\mathrm{Sb}_{2} \mathrm{WO}_{6}$ samples [36]. A large number of mesopores (whose diameters are usually smaller than $30 \mathrm{~nm}$ ) were observed in the pore-size distribution curves (inset in Figure 1b-d). The specific surface areas, mean pore sizes, and mean crystallite sizes of the three different SWO samples are listed in Table 1. According to the BET equation and the Barrett-Joyner-Halenda plot, 
the specific surface area of the SWO-60 sample was calculated as $\sim 22.07 \mathrm{~m}^{2} \mathrm{~g}^{-1}$, and the mean pore size appeared at $3.9 \mathrm{~nm}$. According to the Scherrer equation, the mean crystallite size was calculated as $\sim 13.82 \mathrm{~nm}$. In contrast, the specific surface area and the mean pore size of the SWO-45 sample was $\sim 16.79 \mathrm{~m}^{2} \mathrm{~g}^{-1}$ and $3.7 \mathrm{~nm}$, respectively. This specific surface area was much smaller than that of the SWO-60 sample, and the mean crystallite size of SWO-45 was higher than SWO-60. Although the specific surface area of the SWO-75 sample $\left(\sim 22.98 \mathrm{~m}^{2} \mathrm{~g}^{-1}\right)$ was a little higher than the surface area of the SWO-60 sample, the main pore size was smaller than in the SWO-60 sample. It is believed that this mesoporous structure, with appropriate crystallite size, may be favorable for the transport and storage of lithium ions [38].

Table 1. Comparison of $\mathrm{Sb}_{2} \mathrm{WO}_{6}$ samples synthesized by different microwave heating times in terms of specific surface area, mean pore size, and mean crystallite size.

\begin{tabular}{cccc}
\hline Materials & $\begin{array}{c}\text { Specific Surface Area } \\
\left(\mathbf{m}^{\mathbf{2}} \mathbf{g}\right)\end{array}$ & $\begin{array}{c}\text { Mean Pore Size } \\
(\mathbf{n m})\end{array}$ & $\begin{array}{c}\text { Mean Crystallite Size } \\
\mathbf{( n m})\end{array}$ \\
\hline SWO-45 & 16.79 & 3.7 & 15.37 \\
SWO-60 & 22.07 & 3.9 & 13.82 \\
SWO-75 & 22.98 & 3.6 & 13.16 \\
\hline
\end{tabular}

A scanning electron microscope and a transmission electron microscope were carried out to examine the microstructures and morphology of the SWO samples. As depicted in Figure 2a,b, the as-synthesized SWO-45 and SWO-60 samples exhibit similar nanosheet-like morphology. The nanosheets in SWO-45 (Figure 2a) are severely agglomerated and unevenly distributed, whereas the SWO-60 nanosheets are uniformly grown, and the thickness of the nanosheets is 12 21 nm, which might favor the charge transport and ion diffusion as well as the penetration of the electrolyte. In contrast, the SWO-75 sample (Figure 2c) seems to be of nanoparticle assembly, the reason for which may be that the microwave reaction time was too long, resulting in the overgrowth of nanosheets. As depicted in Figure $2 d$, the transmission electron microscope image further confirms flake morphology of the SWO-60 sample. A high-resolution transmission electron microscope (HRTEM) image is depicted in Figure 2e, with interplanar spacing of $3.3 \AA$ in a single nanosheet, which corresponds to the spacing between the (211) crystal plane of the $\mathrm{Sb}_{2} \mathrm{WO}_{6}$. Figure $2 \mathrm{f}$ shows the SAED of SWO-60, indicating that the crystalline structure of SWO-60 is polycrystalline, which agrees well with the X-ray diffraction patterns depicted in Figure 1a.
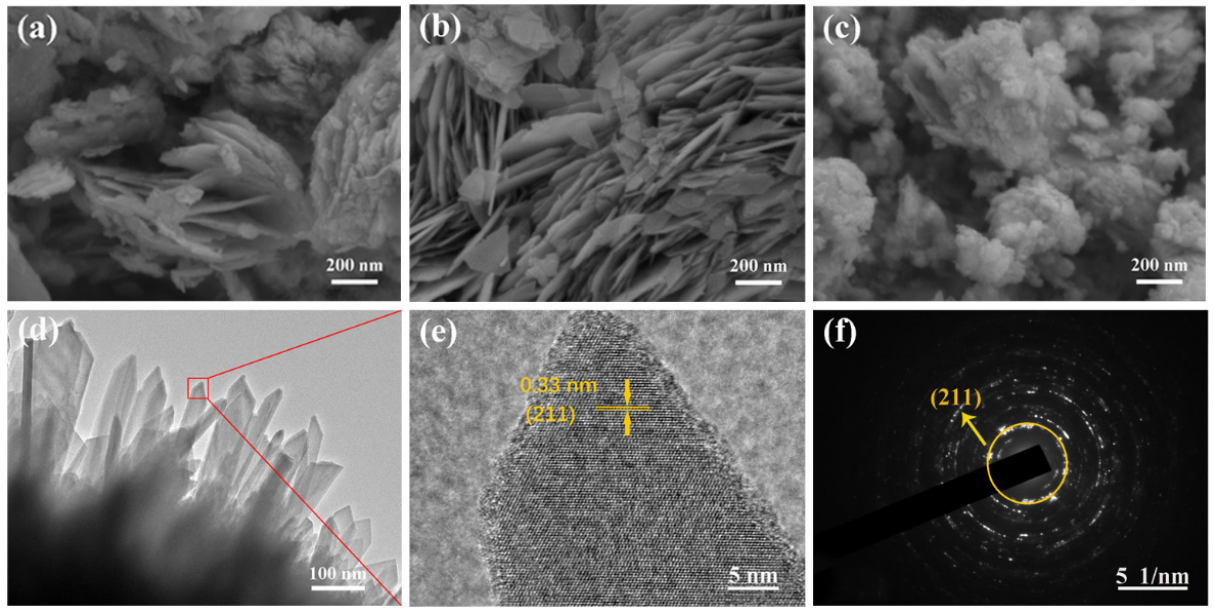

Figure 2. (a-c) Scanning electron microscope (SEM) images of as-prepared SWO-45, SWO-60, and SWO-75 samples; (d) transmission electron microscope (TEM) image of SWO-60; (e) high-resolution transmission electron microscope (HRTEM) image; and (f) selected area electron diffraction (SAED) pattern of the SWO-60 sample. 
To further investigate the chemical composition and valence state of SWO-60, an X-ray photoelectron spectroscopy (XPS) was conducted. In Figure 3b, the binding energies of $530.9 \mathrm{eV}$ and $540.3 \mathrm{eV}$ are in accordance with the $\mathrm{Sb} 3 \mathrm{~d}_{5 / 2}$ and $\mathrm{Sb} 3 \mathrm{~d}_{3 / 2}$ with $3^{+}$oxidation state, respectively [39]. In addition, the peak at $531.9 \mathrm{eV}$ is the characteristic of $\mathrm{O} 1 \mathrm{~s}$. In Figure 3c, the peak at $767.9 \mathrm{eV}$ could be attributed to the $\mathrm{Sb} 3 \mathrm{p}_{3 / 2}$ binding energy of $\mathrm{Sb}_{2} \mathrm{WO}_{6}$. Additionally, the peaks at $35.9 \mathrm{eV}, 38.1 \mathrm{eV}$, and $34.5 \mathrm{eV}$ are characteristics of $\mathrm{W} 4 \mathrm{f}_{7 / 2}, \mathrm{~W} 4 \mathrm{f}_{5 / 2}$, and $\mathrm{Sb} 4 \mathrm{~d}$, respectively, and $\mathrm{W} 4 \mathrm{f}_{7 / 2}$ and $\mathrm{W} 4 \mathrm{f}_{5 / 2}$ are in accordance with the oxidation state of $\mathrm{W}^{6+}[40,41]$.
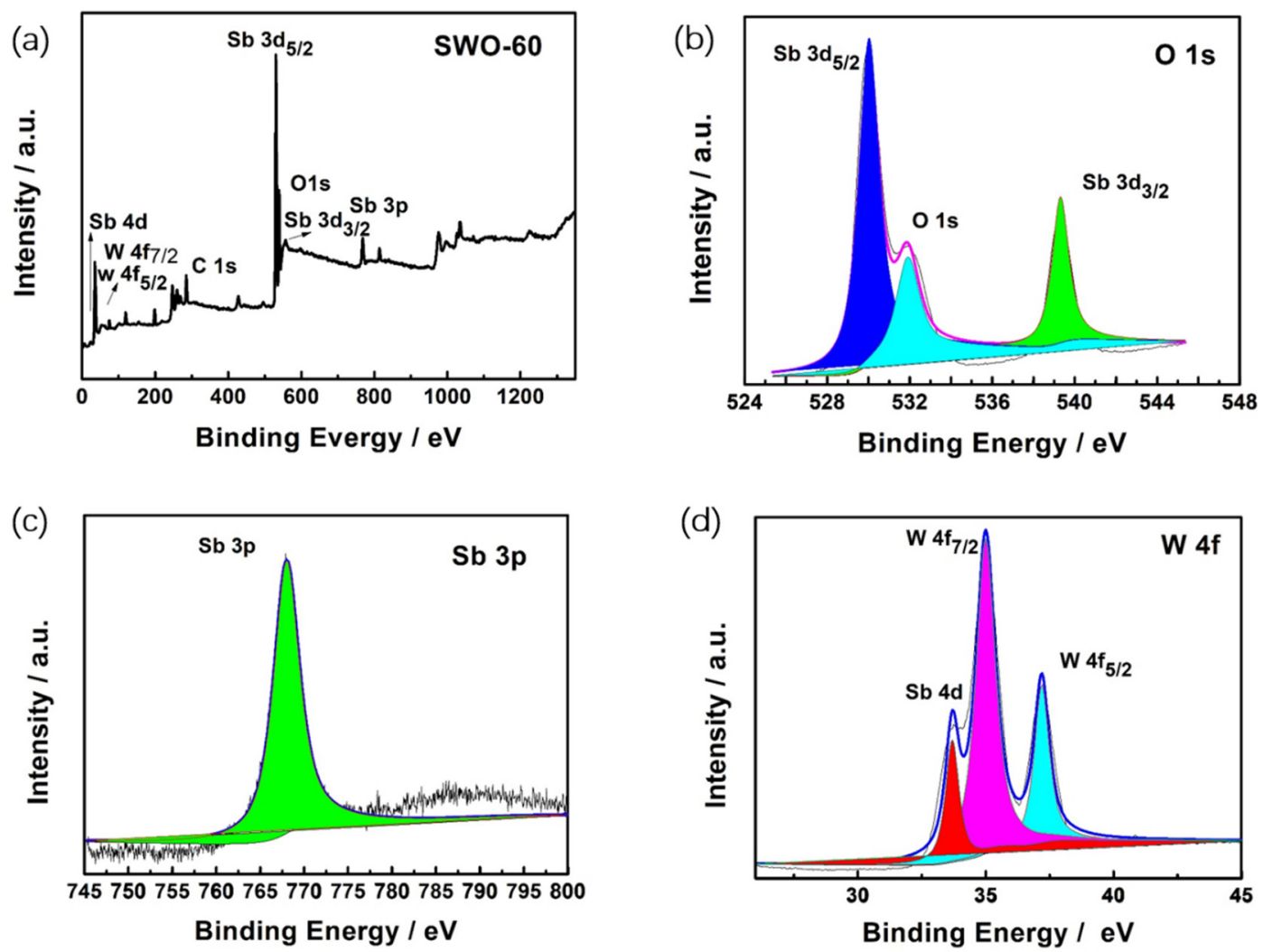

Figure 3. (a) X-ray photoelectron spectroscopy (XPS) survey of the SWO-60 sample, and the high-resolution XPS spectra of (b) Sb 3d and O 1s, (c) Sb 3p, and (d) Sb 4d and W 4f.

\subsection{Electrochemical Performance}

Electrochemical tests were conducted to examine the performances of different SWO samples in lithium-ion batteries (Figure 4). The cyclic voltammetry (CV) of a SWO-60 electrode at a scan rate of $0.5 \mathrm{mV} \mathrm{s}^{-1}$ between $0.01 \mathrm{~V}$ and $3 \mathrm{~V}$ is depicted in Figure $4 \mathrm{a}$. The reduction peak located at $\sim 1.125 \mathrm{~V}$ can be attributed to the formation of solid electrolyte interface (SEI) film, during which $\mathrm{Sb}_{2} \mathrm{WO}_{6} \mathrm{was}$ decomposed and antimony oxide was converted into metallic antimony [35]. The reduction peak centered at $\sim 0.43 \mathrm{~V}$ could be attributed to the alloying-reaction that took place between $\mathrm{Li}$ and $\mathrm{Sb}$, and the oxidation peak of $1.254 \mathrm{~V}$ is related to the dealloying of $\mathrm{Li}_{3} \mathrm{Sb}[35,42]$. As we can see, from the third cycle on, the cyclic voltammetry curves are well overlapped, indicating good reversibility of the SWO-60 electrode. 
(a)

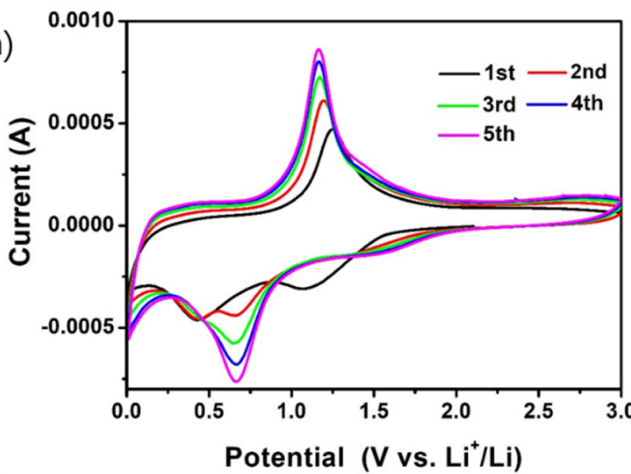

(c)

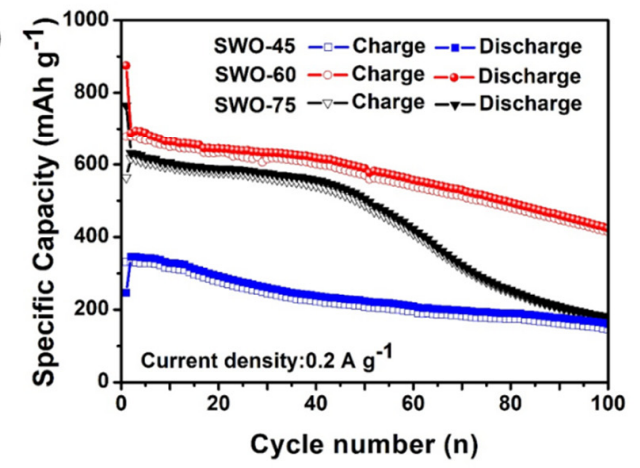

(b)

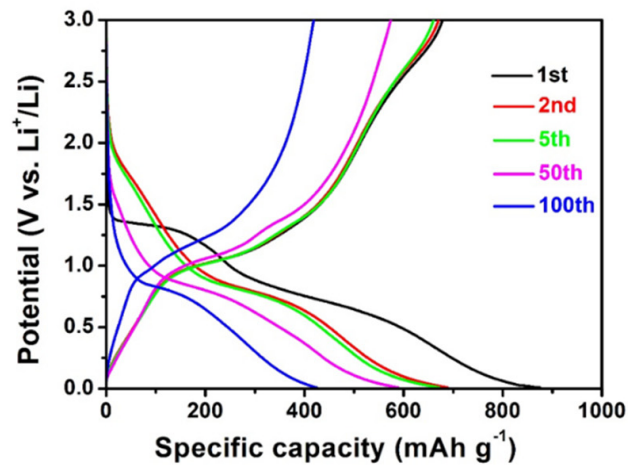

(d)

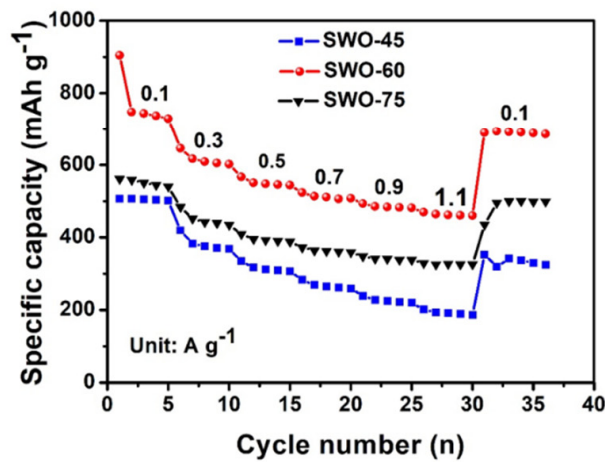

Figure 4. (a) Cyclic voltammetry curves of the SWO-60 electrode at $0.5 \mathrm{mV} \mathrm{s}^{-1}$; (b) cdischarge-charge profile of SWO-60 electrode at different cycles at $0.2 \mathrm{~A} \mathrm{~g}^{-1}$; (c) cycling performances of SWO-45, SWO-60, and SWO-60 electrodes at $0.2 \mathrm{~A} \mathrm{~g} \mathrm{~g}^{-1}$; and (d) rate performance of SWO-45, SWO-60, and SWO-60 electrodes at current density ranging from $0.1-1.1 \mathrm{~A} \mathrm{~g}^{-1}$.

The discharge-charge profile of the SWO-60 electrode in the 1st, 2nd, 5th, 50th, and 100th cycles at $0.2 \mathrm{~A} \mathrm{~g}^{-1}$ is shown in Figure $4 \mathrm{~b}$. During the first cycle, the initial specific discharge and charge capacities of the $\mathrm{Sb}_{2} \mathrm{WO}_{6}$ electrode were $\sim 875.06$ and $\sim 678.42 \mathrm{mAh} \mathrm{g}^{-1}$, respectively, corresponding to $77.52 \%$ in initial coulombic efficiency, which could be attributed to the formation of a solid electrolyte interphase during the first discharge process. As shown in Figure $4 b$, there are two well-defined plateaus at $\sim 1.3$ and $\sim 0.7 \mathrm{~V}$ in the first discharge curve. The plateau of $\sim 1.3 \mathrm{~V}$ disappears after the first cycle, while the $\sim 0.7 \mathrm{~V}$ plateau remains in the following cycles, which is consistent with the $\mathrm{CV}$ discussed above. The cycling stabilities of different $\mathrm{Sb}_{2} \mathrm{WO}_{6}$ electrodes are shown in Figure $4 \mathrm{c}$. The initial specific discharge capacities of the SWO-45, SWO-60, and SWO-75 electrodes are 246.03, 875.06 , and $764.5 \mathrm{mAh} \mathrm{g}^{-1}$ at $0.2 \mathrm{~A} \mathrm{~g}^{-1}$, respectively. The discharge capacities of the SWO-45 and SWO-75 electrodes decrease rapidly, the specific discharge capacities of which undergo a decrease of $\sim 49 \%$ and $\sim 69 \%$, respectively, from the 2 nd to the 100th cycle, that is, they decrease at a rate of $\sim 1.9$ and $\sim 4.4 \mathrm{mAh} \mathrm{g}^{-1}$ per cycle, respectively. In contrast, the reversible capacity of the SWO-60 electrode still delivers $424.22 \mathrm{mAh} \mathrm{g}^{-1}$ at $0.2 \mathrm{~A} \mathrm{~g}^{-1}$ after 100 cycles, corresponding to a decrease of $\sim 39 \%$, which is less than the other two electrodes, which may be associated with the uniform distributed nanosheets structure. However, as mentioned in the literature, the cycling stability of SWO-60 is inferior to $\mathrm{Sb}_{2} \mathrm{WO}_{6}$ for sodium-ion batteries [29], which may be attributed to the poor conductivity of SWO-60 [27], and its cycling stability could be improved through compositing with amorphous carbon, graphene, and other materials with higher conductivity, such as conducting polymers. Figure $4 \mathrm{~d}$ illustrates the rate-performance of three electrodes at current densities ranging from 0.1 to $1.1 \mathrm{~A} \mathrm{~g}^{-1}$. The SWO-60 electrode displays reversible discharge capacities of 743.9, 513.7, and $462.2 \mathrm{mAh} \mathrm{g}^{-1}$ at $0.1,0.7$, and $1.1 \mathrm{~A} \mathrm{~g}^{-1}$, respectively. The SWO-60 electrode can still deliver $703.6 \mathrm{~mA} \mathrm{~h} \mathrm{~g}^{-1}$ when the current density reverts to $0.1 \mathrm{~A} \mathrm{~g}^{-1}$, which is much higher than the SWO-45 and SWO-75 electrodes. The excellent rate performance of SWO-60 could be associated with its unique nanosheets morphology, which facilitates rapid lithium-ion conduction and transportation [43]. 
In order to investigate the electrochemical kinetics of different kinds of electrodes, electrochemical impedance spectroscopy measurements were carried out from $0.1 \mathrm{~Hz}$ to $100 \mathrm{kHz}$ in frequency. Figure 5a,b shows the Nyquist plots of three kinds of electrodes in initial their states and after 200 discharge-charge cycling at $0.2 \mathrm{~A} \mathrm{~g}^{-1}$, respectively. In the impedance spectra, the semicircles in the high-frequency region correspond to the charge-transfer resistance $\left(R_{\mathrm{ct}}\right)$ in the interface of electrodes and electrolyte, and the inclined lines during the low-frequency region are attributed to insertion of lithium ions into the negative electrode [44]. In Figure 5a, the charge transfer resistance of a battery with a SWO-60 electrode $(332.8 \Omega)$ is much smaller than those of the SWO-45 (998.4 $\Omega$ ) and SWO-75 (477.3 $\Omega$ ) batteries, which is consistent with the good cycling stability of the SWO-60 electrode. Figure 5b shows the EIS of SWO-45, SWO-60, and SWO-75 cells after 200 cycles at $0.2 \mathrm{~A} \mathrm{~g}^{-1}$. After cycling, the cell with the SWO-60 electrode also exhibited the lowest charge transfer resistance, which is in good agreement with the fact that the SWO-60 electrode showed the best electrochemical properties.

(a)

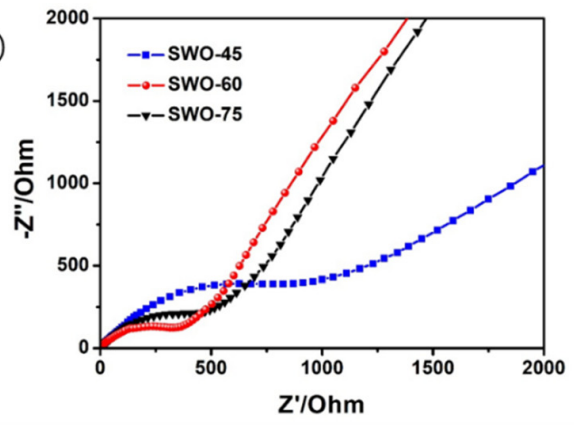

(b)

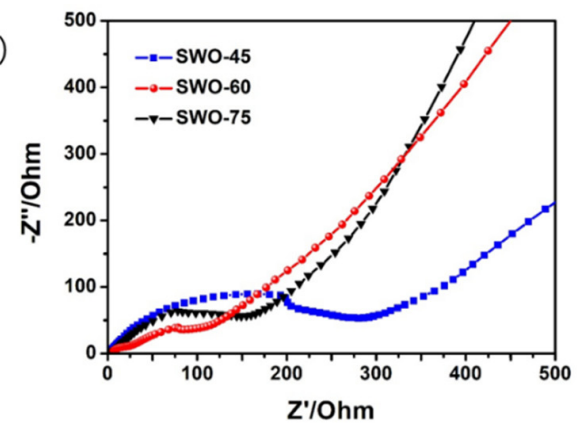

Figure 5. Nyquist plots of different electrodes (a) before cycling and (b) after 200 cycles at $0.2 \mathrm{~A} \mathrm{~g}^{-1}$.

To investigate the effect of different microwave hydrothermal times on the structural stability of electrodes, the morphology of electrodes was examined after 200 cycles at $0.2 \mathrm{~A} \mathrm{~g}^{-1}$ (Figure 6). Figure 6a-c shows the morphology of the SWO-45, SWO-60, and SWO-75 electrodes after cycling, respectively. After 200 cycles, it was found that there were many large cracks and pulverizations in the SWO-45 and SWO-75 electrodes, as shown in Figure 6a,c, respectively. By contrast, the SWO-60 electrode retained its structural integrity even after 200 cycles, as shown in Figure $6 \mathrm{~b}$.

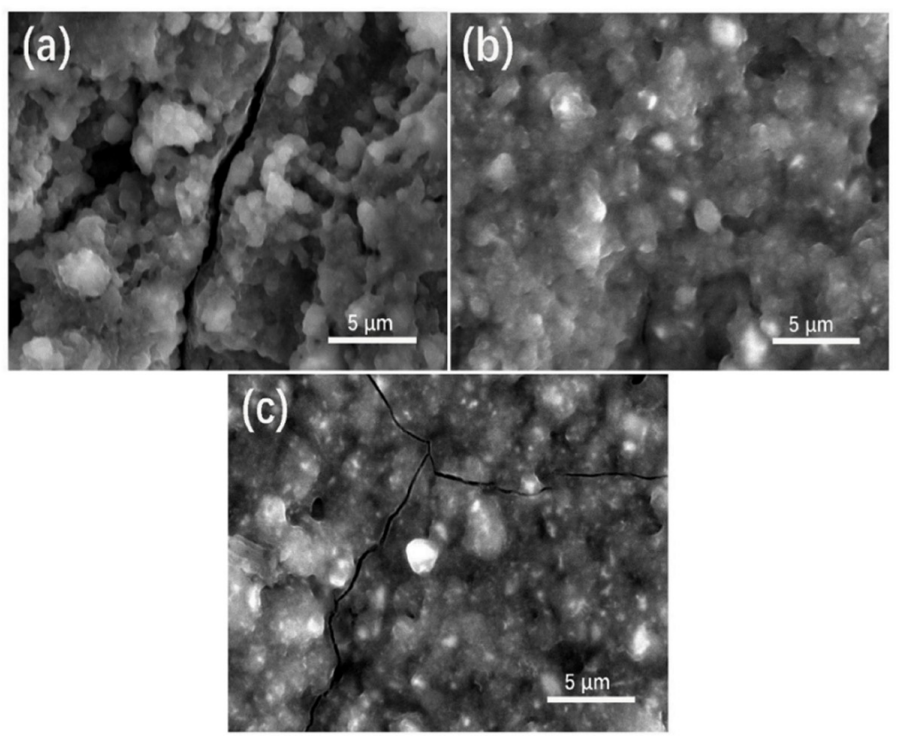

Figure 6. Scanning electron microscope images of (a) SWO-45, (b) SWO-60, and (c) SWO-75 electrodes after 200 cycles at $0.2 \mathrm{~A} \mathrm{~g}^{-1}$. 


\section{Conclusions}

In summary, mesoporous $\mathrm{Sb}_{2} \mathrm{WO}_{6}$ nanosheets were successfully fabricated using a microwave hydrothermal method and were systematically investigated as negative electrodes for LIBs. When the microwave reaction time is $60 \mathrm{~min}$, SWO-60 exhibits the highest reversible capacity and the best rate performance. The good electrochemical performance of the SWO-60 electrode may be ascribed to its uniformly distributed nanosheets structure. Due to the limited inherent electronic conductivity of SWO, our future work will focus on combining SWO with other materials with higher conductivities, such as heteroatom-doped nanocarbon materials and graphene, to further improve their electrochemical performance.

Author Contributions: Y.L., W.Z., and F.R. conceived and designed the experiments; Y.W., F.W., and Z.L. performed the experiments; Y.W., J.L., and K.P. analyzed the data; Y.W. wrote the paper; Y.L., G.W., M.C., and S.W. revised the paper. All the authors have discussed the results and commented on the manuscript.

Funding: This work was supported by the Program for Changjiang Scholars and Innovative Research Team in University (IRT_16R21), the Chinese 02 Special Fund (2017ZX02408003), the Key Research Projects of Colleges and Universities in the Henan Province (15A430023), the Scientific and Technological Project of Henan Province (182102210297), Open Fund of National Joint Engineering Research Center for abrasion control and molding of metal materials (HKDNM201807), Scientific Research Starting Foundation for Ph.D. of Henan University of Science and Technology (13480065), Science Foundation for Youths of Henan University of Science and Technology (2013QN006), and the Student Research Training Plan of Henan University of Science and Technology (2018029, 2019031).

Acknowledgments: Y. W. is grateful for the valuable discussion and help from Huijie Wei from School of Materials Science and Engineering, Henan University of Science and Technology.

Conflicts of Interest: The authors declare no conflict of interest.

\section{References}

1. Chu, S.; Cui, Y.; Liu, N. The path towards sustainable energy. Nat. Mater. 2017, 16, 16-22. [CrossRef]

2. Tarascon, J.M.; Armand, M. Issues and challenges facing rechargeable lithium batteries. Nature 2001, 414, 359-367. [CrossRef] [PubMed]

3. Armand, M.; Tarascon, J.M. Building better batteries. Nature 2008, 451, 652-657. [CrossRef] [PubMed]

4. Goodenough, J.B.; Kim, Y. Challenges for Rechargeable Li Batteries. Chem. Mater. 2010, 22, 587-603. [CrossRef]

5. Wu, H.B.; Chen, J.S.; Hng, H.H.; Lou, X.W. Nanostructured metal oxide-based materials as advanced anodes for lithium-ion batteries. Nanoscale 2012, 4, 2526-2542. [CrossRef] [PubMed]

6. Cheng, C.; Geng, T.; Du, C.; Zuo, P.; Cheng, X.; Ma, Y.; Yin, G. Oxygen vacancies in $\mathrm{SnO}_{2}$ surface coating to enhance the activation of layered Li-Rich $\mathrm{Li}_{1.2} \mathrm{Mn}_{0.54} \mathrm{Ni}_{0.13} \mathrm{Co}_{0.13} \mathrm{O}_{2}$ cathode material for Li-ion batteries. J. Power Sources 2016, 331, 91-99. [CrossRef]

7. Wang, Y.; Wang, Z.; Lei, D.; Lv, W.; Zhao, Q.; Ni, B.; Liu, Y.; Li, B.; Kang, F.; He, Y.-B. Spherical Li Deposited inside 3D Cu Skeleton as Anode with Ultrastable Performance. ACS Appl. Mater. Interfaces 2018, 10, 20244-20249. [CrossRef]

8. Zheng, J.-C.; Yang, Z.; He, Z.-J.; Tong, H.; Yu, W.-J.; Zhang, J.-F. In situ formed $\mathrm{LiNi}_{0.8} \mathrm{Co}_{0.15} \mathrm{Al}_{0.05} \mathrm{O}_{2} @ \mathrm{Li}_{4} \mathrm{SiO}_{4}$ composite cathode material with high rate capability and long cycling stability for lithium-ion batteries. Nano Energy 2018, 53, 613-621. [CrossRef]

9. Liu, Y.; Zhai, X.; Yang, K.; Wang, F.; Wei, H.; Zhang, W.; Ren, F.; Pang, H. Mesoporous $\mathrm{NH}_{4} \mathrm{NiPO}_{4}$ center dot $\mathrm{H}_{2} \mathrm{O}$ for High-Performance Flexible All-Solid-State Asymmetric Supercapacitors. Front. Chem. $2019,7$. [CrossRef]

10. Guo, X.T.; Zhang, Y.Z.; Zhang, F.; Li, Q.; Anjum, D.H.; Liang, H.F.; Liu, Y.; Liu, C.S.; Alshareef, H.N.; Pang, $\mathrm{H}$. A novel strategy for the synthesis of highly stable ternary $\mathrm{SiO}_{\mathrm{x}}$ composites for Li-ion-battery anodes. J. Mater. Chem. A 2019, 7, 15969-15974. [CrossRef]

11. Peng, T.; Liu, C.; Hou, X.Y.; Zhang, Z.W.; Wang, C.L.; Yan, H.L.; Lu, Y.; Liu, X.M.; Luo, Y.S. Control Growth of Mesoporous Nickel Tungstate Nanofiber and Its Application as Anode Material for Lithium-Ion Batteries. Electrochim. Acta 2017, 224, 460-467. [CrossRef] 
12. Hao, X.G.; Zhao, Q.; Su, S.M.; Zhang, S.Q.; Ma, J.B.; Shen, L.; Yu, Q.P.; Zhao, L.; Liu, Y.; Kang, F.Y.; et al. Constructing Multifunctional Interphase between $\mathrm{Li}_{1.4} \mathrm{Al}_{0.4} \mathrm{Ti}_{1.6}\left(\mathrm{PO}_{4}\right)_{3}$ and $\mathrm{Li}$ Metal by Magnetron Sputtering for Highly Stable Solid-State Lithium Metal Batteries. Adv. Energy Mater. 2019, 9, 1901604. [CrossRef]

13. Peng, T.; Hou, X.Y.; Liu, C.; Yu, Q.H.; Luo, R.J.; Yan, H.L.; Lu, Y.; Liu, X.M.; Luo, Y.S. Controlled synthesis of hierarchical $\mathrm{CoMn}_{2} \mathrm{O}_{4}$ nanostructures for flexible all-solid-state battery-type electrodes. J. Solid State Electrochem. 2017, 21, 1579-1587. [CrossRef]

14. Wu, N.T.; Shen, J.K.; Sun, L.; Yuan, M.Y.; Shao, Y.Y.; Ma, J.M.; Liu, G.L.; Guo, D.L.; Liu, X.M.; He, Y.B. Hierarchical N-doped graphene coated 1D cobalt oxide microrods for robust and fast lithium storage at elevated temperature. Electrochim. Acta 2019, 310, 70-77. [CrossRef]

15. Kang, B.; Ceder, G. Battery materials for ultrafast charging and discharging. Nature 2009, 458, $190-193$. [CrossRef]

16. Wu, H.; Chan, G.; Choi, J.W.; Ryu, I.; Yao, Y.; McDowell, M.T.; Lee, S.W.; Jackson, A.; Yang, Y.; Hu, L.B.; et al. Stable cycling of double-walled silicon nanotube battery anodes through solid-electrolyte interphase control. Nat. Nanotechnol. 2012, 7, 309-314. [CrossRef]

17. Whittingham, M.S. Lithium batteries and cathode materials. Chem. Rev. 2004, 104, 4271-4301. [CrossRef]

18. Kwasi-Effah, C.C.; Rabczuk, T. Dimensional analysis and modelling of energy density of lithium-ion battery. J. Energy Storage 2018, 18, 308-315. [CrossRef]

19. Liu, Y.; Wei, H.; Wang, C.; Wang, F.; Wang, H.; Zhang, W.; Wang, X.; Yan, C.; Kim, B.H.; Ren, F. Nitrogen-Doped Carbon Coated $\mathrm{WS}_{2}$ Nanosheets as Anode for High-Performance Sodium-Ion Batteries. Front. Chem. 2018, 6. [CrossRef]

20. Wang, F.; Liu, Y.; Zhao, Y.; Wang, Y.; Wang, Z.; Zhang, W.; Ren, F. Facile Synthesis of Two-Dimensional Porous $\mathrm{MgCo}_{2} \mathrm{O}_{4}$ Nanosheets as Anode for Lithium-Ion Batteries. Appl. Sci. 2018, 8, 22. [CrossRef]

21. Liu, G.; Cui, J.; Luo, R.; Liu, Y.; Huang, X.; Wu, N.; Jin, X.; Chen, H.; Tang, S.; Kim, J.-K.; et al. 2D MoS 2 grown on biomass-based hollow carbon fibers for energy storage. Appl. Surf. Sci. 2019, 469, 854-863. [CrossRef]

22. Liu, Y.; Wang, H.C.; Yang, K.K.; Yang, Y.N.; Ma, J.Q.; Pan, K.M.; Wang, G.X.; Ren, F.Z.; Pang, H. Enhanced Electrochemical Performance of $\mathrm{Sb}_{2} \mathrm{O}_{3}$ as an Anode for Lithium-Ion Batteries by a Stable Cross-Linked Binder. Appl. Sci. 2019, 9, 2677. [CrossRef]

23. Kasnatscheew, J.; Wagner, R.; Winter, M.; Cekic-Laskovic, I. Interfaces and Materials in Lithium Ion Batteries: Challenges for Theoretical Electrochemistry. Top. Curr. Chem. 2018, 376, 29. [CrossRef]

24. Wang, H.; Wei, Y.J.; Wang, J.T.; Long, D.H. Polymer-chelation synthesis of compositionally homogeneous $\mathrm{LiNi}_{1 / 3} \mathrm{Co}_{1 / 3} \mathrm{Mn}_{1 / 3} \mathrm{O}_{2}$ crystals for lithium-ion cathode. Electrochim. Acta 2018, 269, 724-732. [CrossRef]

25. Wang, H.; Yang, X.; Wu, Q.; Zhang, Q.; Chen, H.; Jing, H.; Wang, J.; Mi, S.-B.; Rogach, A.L.; Niu, C. Encapsulating Silica/Antimony into Porous Electrospun Carbon Nanofibers with Robust Structure Stability for High-Efficiency Lithium Storage. ACS Nano 2018, 12, 3406-3416. [CrossRef]

26. Zeng, C.; Weng, W.; Lv, T.; Xiao, W. Low-Temperature Assembly of Ultrathin Amorphous $\mathrm{MnO}_{2} \mathrm{Nanosheets}$ over $\mathrm{Fe}_{2} \mathrm{O}_{3}$ Spindles for Enhanced Lithium Storage. ACS Appl. Mater. Interfaces 2018, 10, 30470-30478. [CrossRef]

27. Shim, H.W.; Cho, I.S.; Hong, K.S.; Lim, A.H.; Kim, D.W. Wolframite-type ZnWO $\mathrm{Zn}_{4}$ Nanorods as New Anodes for Li-Ion Batteries. J. Phys. Chem. C 2011, 115, 16228-16233. [CrossRef]

28. Sharma, N.; Rao, G.V.S.; Chowdari, B.V.R. Electrochemical properties of carbon-coated $\mathrm{CaWO}_{4}$ versus $\mathrm{Li}_{\text {. }}$ Electrochim. Acta 2005, 50, 5305-5312. [CrossRef]

29. Hyun-Woo, S.; In-Sun, C.; Kug Sun, H.; Won Il, C.; Dong-Wan, K. Li electroactivity of iron (II) tungstate nanorods. Nanotechnology 2010, 21, 465602.

30. Zhang, L.S.; Bai, Q.L.; Jin, K.; Wang, L.Z.; Zhang, Y.; Song, Y.H. Synthesis and electrochemical performance of $\mathrm{Bi}_{2} \mathrm{WO}_{6}$ /graphene composite as anode material for lithium-ion batteries. Mater. Lett. 2015, 141, 88-91. [CrossRef]

31. Zhang, L.S.; Zhao, Z.J.; Xia, T.C.; Zhang, S.L.; Li, X.F.; Zhang, A.Q. Anchoring $\mathrm{Bi}_{2} \mathrm{WO}_{6}$ nanoparticles on 3D graphene frameworks for enhanced lithium storage. Mater. Lett. 2018, 210, 345-349. [CrossRef]

32. Singh, A.; Dutta, D.P.; Roy, M.; Tyagi, A.K.; Fulekar, M.H. Sonochemical synthesis, characterization, and photocatalytic properties of $\mathrm{Bi}_{2-x} \mathrm{Sb}_{x} \mathrm{WO}_{6}$ nanorods. J. Mater. Sci. 2014, 49, 2085-2097. [CrossRef]

33. Yang, C.Y.; Yang, X.J.; Li, F.; Li, T.H.; Cao, W. Controlled synthesis of hierarchical flower-like $\mathrm{Sb}_{2} \mathrm{WO}_{6}$ microspheres: Photocatalytic and superhydrophobic property. J. Ind. Eng. Chem. 2016, 39, 93-100. [CrossRef] 
34. Hu, S.P.; Xu, C.Y.; Ma, F.X.; Cao, L.; Zhen, L. Solvothermal synthesis of orthorhombic $\mathrm{Sb}_{2} \mathrm{WO}_{6}$ hierarchical structures and their visible-light-driven photocatalytic activity. Dalton Trans. 2014, 43, 8439-8445. [CrossRef]

35. Wang, P.; Xie, S.M.; She, Y.Y.; Fan, W.G.; Leung, M.K.H.; Wane, H.K. Microwave-Hydrothermal Synthesis of Hierarchical $\mathrm{Sb}_{2} \mathrm{WO}_{6}$ Nanostructures as a New Anode Material for Sodium Storage. Chemistryselect 2019, 4, 1078-1083. [CrossRef]

36. Chen, S.Q.; Zhou, M.Y.; Li, T.H.; Cao, W. Synthesis of Ag-loaded $\mathrm{Sb}_{2} \mathrm{WO}_{6}$ microsphere with enhanced photocatalytic ability for organic dyes degradations under different light irradiations. J. Mol. Liq. 2018, 272, 27-36. [CrossRef]

37. Liu, Y.; Hori, A.; Kusaka, S.; Hosono, N.; Li, M.; Guo, A.; Du, D.; Li, Y.; Yang, W.; Ma, Y.; et al. Microwave-Assisted Hydrothermal Synthesis of $\mathrm{Al}(\mathrm{OH})(1,4-\mathrm{NDC})$ Membranes with Superior Separation Performances. Chem. Asian J. 2019. [CrossRef]

38. Park, H.C.; Lee, K.H.; Lee, Y.W.; Kim, S.J.; Kim, D.M.; Kim, M.C.; Park, K.W. Mesoporous molybdenum nitride nanobelts as an anode with improved electrochemical properties in lithium ion batteries. J. Power Sources 2014, 269, 534-541. [CrossRef]

39. Lu, X.; Wang, Z.Y.; Lu, L.; Yang, G.; Niu, C.M.; Wang, H.K. Synthesis of Hierarchical $\mathrm{Sb}_{2} \mathrm{MoO}_{6}$ Architectures and Their Electrochemical Behaviors as Anode Materials for Li-Ion Batteries. Inorg. Chem. 2016, 55, 7012-7019. [CrossRef]

40. Wu, X.; Yao, S.Y. Flexible electrode materials based on $\mathrm{WO}_{3}$ nanotube bundles for high performance energy storage devices. Nano Energy 2017, 42, 143-150. [CrossRef]

41. Su, Y.B.; Zhang, H.J.; Liang, P.; Liu, K.; Cai, M.Y.; Huang, Z.Y.; Wang, C.A.; Zhong, M.L. A new binder-free and conductive-additive-free $\mathrm{TiO}_{2} / \mathrm{WO}_{3}-\mathrm{W}$ integrative anode material produced by laser ablation. J. Power Sources 2018, 378, 362-368. [CrossRef]

42. Lu, X.; Wang, P.; Liu, K.; Niu, C.M.; Wang, H.K. Encapsulating nanoparticulate $\mathrm{Sb} / \mathrm{MoO}_{\mathrm{x}}$ into porous carbon nanofibers via electrospinning for efficient lithium storage. Chem. Eng. J. 2018, 336, 701-709. [CrossRef]

43. Bai, J.; Zhao, B.C.; Zhou, J.F.; Fang, Z.T.; Li, K.Z.; Ma, H.Y.; Dai, J.M.; Zhu, X.B.; Sun, Y.P. Improved Electrochemical Performance of Ultrathin $\mathrm{MoS}_{2}$ Nanosheet/Co Composites for Lithium-Ion Battery Anodes. Chemelectrochem 2019, 6, 1930-1938. [CrossRef]

44. Jin, J.; Huang, S.-Z.; Shu, J.; Wang, H.-E.; Li, Y.; Yu, Y.; Chen, L.-H.; Wang, B.-J.; Su, B.-L. Highly porous $\mathrm{TiO}_{2}$ hollow microspheres constructed by radially oriented nanorods chains for high capacity, high rate and long cycle capability lithium battery. Nano Energy 2015, 16, 339-349. [CrossRef] 